\title{
Fire resistance of bearing walls in light steel frame (LSF) structures including various insulation filler materials by finite element method
}

\begin{abstract}
Using prefabricated structure in lightweight construction is the new method in both industry and civil engineering. Lightweight Steel Frame (LSF) becomes more valuable in the construction industry due to low cost, low weight, high speed of installation and resistance to environmental conditions. Cold-rolled form lightweight load-bearing wall is consisting of a thin sheet of steel with C-shaped sections (STUD), thermal insulation filler and cover sheets (Plaster Board). However, regardless of existing plasterboard protection the thin-walled steel sections heat up quickly and lose their strength under fire conditions. The main goal of the current study is an evaluation of thermal capacity and bearing strength of lightweight walls in terms of cellulosic fire condition analytically. The variable parameters are insulation filler materials (polystyrene, polystyrene concrete) and axial load. The Abaqus finite element software was used for modeling and analyzing of fire loads. Lightweight concrete fillers increase the axial bearing capacity of walls sustainably and polystyrene filler improved the fire resistance of walls.
\end{abstract}

Keyword: Light gauge steel frame walls; Insulation filler; Polystyrene; Fire resistance; Finite element analysis 